\title{
THE EFFECT OF POSTURAL RESTRICTIONS IN THE TREATMENT OF BENIGN PAROXYSMAL POSITIONAL VERTIGO: RANDOMIZED CONTROL TRIAL
}

\author{
Anil R Muragod ${ }^{* 1}$, Sanjiv Kumar ${ }^{2}$. \\ ${ }^{* 1}$ MPT, Assistant Professor. KLEU Institute of Physiotherapy, Belgavi. Karnataka. India. \\ ${ }^{2}$ MPT, PhD Professor. KLEU Institute of Physiotherapy, Belgavi. Karnataka. India. \\ ABSTRACT
}

Background and purpose: The Benign Paroxysmal Positional Vertigo (BPPV) is defined as disorder of the inner ear characterized by repeated episodes of positional vertigo. The BPPV can be managed with various office procedures like Epley's maneuver, Samont maneuver and Gans Maneuvers etc. After these maneuvers postural restrictions are generally advised so the aim of study was to determine the effectiveness postural restrictions after Epley's maneuver.

Materials and Methods: 30 subjects with BPPV were included in the study after obtaining institutional ethical clearance. After fulfillment of inclusion criteria and exclusion criteria the informed consent was obtained from all the subjects. The convenient sampling design was used. The subjects were assigned in to two groups by envelop method. Group A received Epleys maneuver with postural restrictions and group B received only Epleys maneuver. Dizziness handicap inventory (DHI) measures were taken before the maneuvers and after one week of follow-up.

Results: In both Epleys maneuver with postural restriction and in Epleys maneuver group shows statistically significant decrease in $\mathrm{DHI}$ scores with $\mathrm{p}$ value of .001 by using paired $t$ test.

Conclusion: Both Epleys maneuver with postural restrictions and Epleys maneuver group are equally effective in the treatment of BPPV. In routine BPPV treatment we can stop advising the postural restrictions to the subjects so that we can avoid the discomfort to the subjects because of postural restrictions.

KEY WORDS: Vestibular rehabilitation, BPPV, DHI, Epleys maneuver, Postural restrictions.

Address for correspondence: Dr Anil R Muragod, Assistant Professor, HOD of Geriatric Physiotherapy KLEU Institute of Physiotherapy, JNMC,Campus, Nehrunagar, Belgavi-590010, Karnataka, India. Mobile no 09164694970. E-Mail: dranilphysio@rediffmail.com.

\begin{tabular}{|l|l|}
\hline \multicolumn{3}{|c|}{ Access this Article online } \\
\hline Quick Response code & International Journal of Physiotherapy and Research \\
ISSN 2321- 1822
\end{tabular}

\section{INTRODUCTION}

The Benign Paroxysmal Positional Vertigo (BPPV) is defined as disorder of the inner ear characterized by repeated episodes of positional vertigo. Positional vertigo is defined as spinning sensation produced by changes in head position relative to gravity [1]. BPPV is one of the most common conditions which cause the vertigo. Vertigo is defined as the illusion of moment [2]. BPPV is characterized by brief episodes of vertigo when the head is moved into certain positions. In BPPV subjects commonly report vertigo triggered by lying down, rolling over in bed, bending over \& looking up, common situations in which vertigo is provoked including getting out of bed, gardening, washing hair in shower, and going to the dentist or beauty parlor [3]. BPPV is reported to comprise up to 
$43 \%$ of the patient population in an otology clinic [4]. The BPPV occur due to the otoliths (otoconia) becoming dislodged from the utricle $\&$ falling in to the semicircular canals (SCCS). There are two mechanisms which explain BPPV (1) Cupulolith-iasis (2) Canalithiasis. The fragments of outoconia break away \& adhere to the cupula of one of the SCCS is called cupulolithiasis. In Canalithiasis the otoconia are floating freely in one of the SCCS [5]. There are three SCCs. Anterior, Posterior, \& Horizontal, among all SCCs the posterior canal BPPV is very common because of anatomical orientation. $60-90 \%$ of all the cases are of posterior canal BPPV. The cause for BPPV is mostly unknown (idiopathic) cause, but may develop secondary to various disorders that damage the inner ear, head trauma, after mastoid surgery or engage in persistent head tilt positions [6]. The BPPV can be diagnosed by Dix Hallipike maneuver \& supine roll test. Dix Hallipike maneuver can identify the canal involvement depending on the direction of nystagmus and also considered as gold standard test for posterior canal BPPV. Supine roll test is used to diagnose the lateral (Horizontal) canal involvement $[1,3]$.

Repeated canalith repositioning maneuver and Brand Daroff exercise fails for BPPV rarely the surgical management like singular neurectomy and canal plugging surgeries are done. The medical management for BPPV is vestibular suppressant drugs. The physiotherapy management includes. Epley's maneuver, Samont maneuver, Brand Daroff exercise, Gans maneuver and Epley's, Semont maneuver have been modified to enable a patient to self treat etc $[1,7]$. Postural restrictions were advised to the subjects to keep your head upright. Do not pitch your head up or down Try to keep your head vertical, as if trying to balance a book on it. Side-to-side turns are okay. Do not lay flat. Try to sleep propped-up about 30 degrees for two days. To wear cervical collar for two days post treatment. Avoid sleeping on the side of the treated ear for three days $[8,9]$. So the study was intended to know the effectiveness postural restrictions after of Epley's maneuver in BPPV.

\section{MATERIALS AND METHODS}

The study was approved by institutional ethical committee prior to the commencement of the study. Written informed consent was obtained after fulfillment of inclusion criteria and exclusion criteria from all the subjects after explaining the purpose of the study. The subjects were included from KLES Dr Prabhakar Kore Hospital and Medical Research Center Belgavi. Inclusion criteria were all the subjects with posterior canal BPPV, subjects with positive Dix Hallipike maneuver were included. Exclusion criteria were subjects with central vertigo, Vertebrobasilar artery insufficiency VBI, musculoskeletal problem at neck and back, neurological problems.

The Dix Hallpike maneuver was performed in the fallowing steps [10]. The subjects sits on examination table in long sitting position and therapist turns the head horizontally to 45 degrees (Fig.1). As the examiner maintains the 45 degrees rotation, the patient is quickly brought straight back so that the neck is extended 30 degrees beyond horizontal. The therapist must look for nystagmus and ask the patient if vertigo is being experienced. The patient is then slowly brought back to the starting position, and the other side is tested. The side that reproduces nystagmus and vertigo is the side that has benign paroxysmal positional vertigo [BPPV] (Fig.2).

30 subjects with positive Dix Hallpike maneuver subjects were included in the study by convenient sampling were randomly allocated by envelop method in to two groups. Group A, received Epleys maneuver with postural restrictions. Group B received Epleys maneuver only.

In both groups Epleys maneuver was performed for BPPV the steps were as fallows [7].

The patient's head is first rotated toward the involved side, pictured here as the left (Fig. 3).

The patient is then moved into the Hallpike-Dix position with the affected left ear toward the ground (Fig. 4). Next, the head is rotated 180 degrees to the right side. It is important to maintain the 30-degree neck extension during this step (Fig. 5). The patient is rolled onto the right shoulder and (Fig. 6). Slowly brought up to sitting position, head still rotated to the right (Fig. 7).After Epleys maneuver Group A received postural restriction and were advised to the 
subjects to keep your head upright. Do not pitch your head up or down try to keep your head vertical, as if trying to balance a book on it. Side-to-side turns are okay. Do not lay flat. Try to sleep propped-up about 30 degrees for two days. To wear cervical collar for two days post treatment. Avoid sleeping on the side of the treated ear for three days $[8,9]$. Group B did not receive any thing.

All subjects were assessed before the maneuver and after one week with dizziness handicap inventory (DHI) as outcome measure.

Fig. 1: Dix Hallpike maneuver first step.

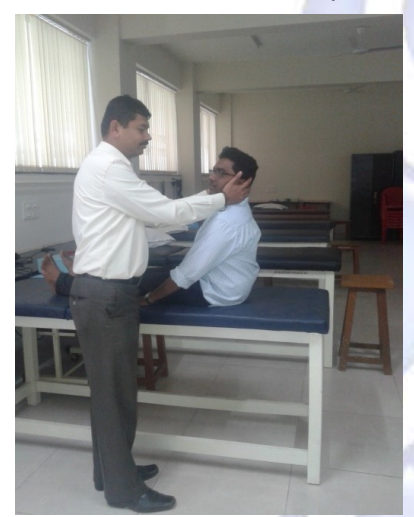

Fig. 3: Epleys maneuver step one.

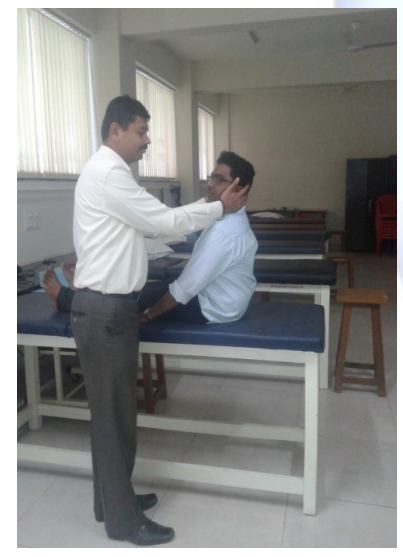

Fig. 5: Epleys maneuver step three.

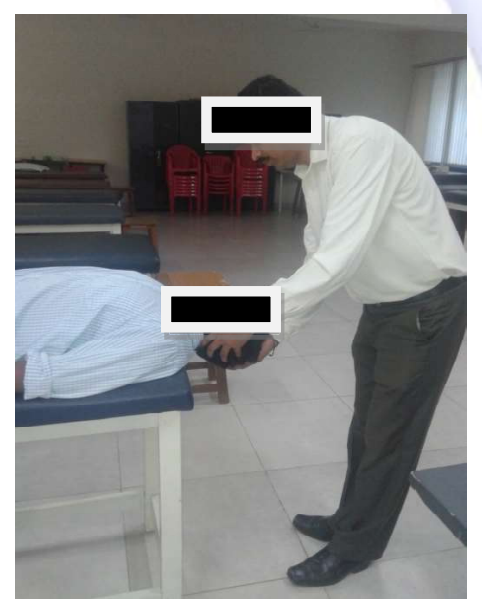

Fig. 6: Epleys maneuver step four.

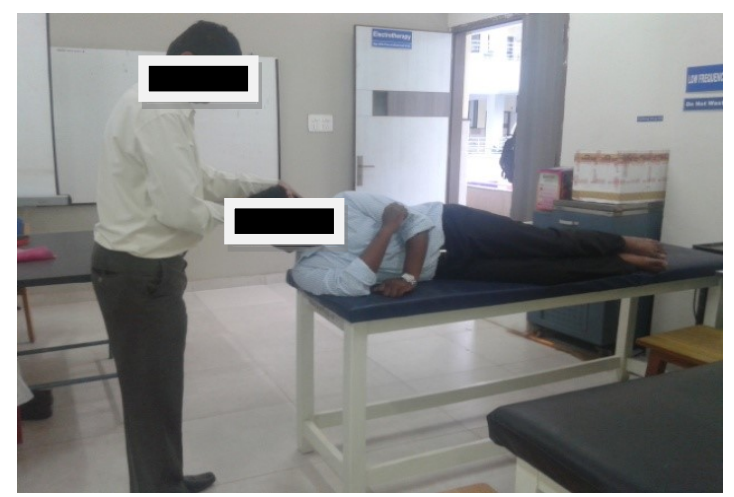

Fig. 7: Epleys maneuver step five.

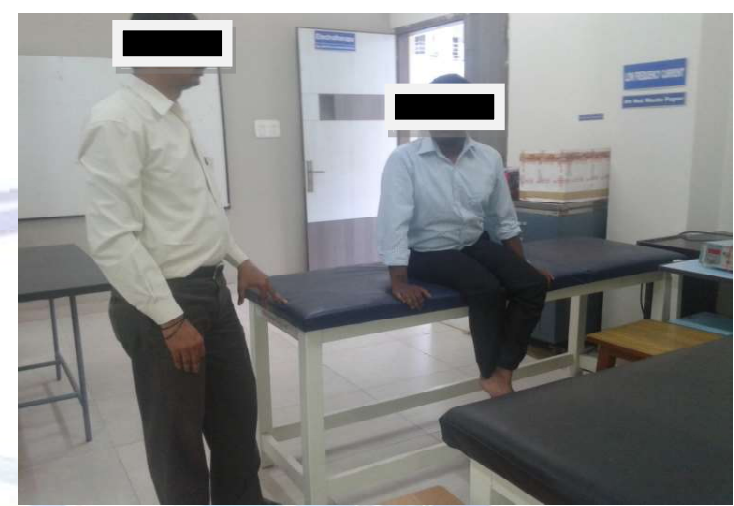

RESULT

Statistical analysis was performed by using SPSS Software. Analysis of various measures like Mean, Slandered deviation, difference, and level of significance was done by Pared t test and unpaired $t$ test

Table1: Demographic Data.

\begin{tabular}{|c|c|c|c|c|}
\hline \multirow{2}{*}{ Groups } & \multirow{2}{*}{$\begin{array}{c}\text { Age } \\
\text { Mean } \pm S D\end{array}$} & \multirow{2}{*}{$\begin{array}{l}\text { Male } \\
\text { Female } \\
\text { ratio }\end{array}$} & \multicolumn{2}{|c|}{ Side affected } \\
\hline & & & Right & Left \\
\hline $\begin{array}{l}\text { Epleys Maneuver with } \\
\text { postural restrictions } \\
\text { (Group A) } n=15\end{array}$ & $50.1 \pm 15.07$ & 6:09 & 8 & 7 \\
\hline $\begin{array}{l}\text { Epleys Maneuver } \\
\text { (Group B) n=15 }\end{array}$ & $54.2 \pm 12.18$ & $5: 10$ & 6 & 9 \\
\hline
\end{tabular}

The demographic data of the study showed, out of 30 subjects recruited. 15 subjects were in Group A and 15 in group B. In group A, 6 were males and 9 were female subjects. In group $B, 5$ were males and 10 were females. The mean total age was 50.1 years with standard deviation 15.07 was in group $A$. and in group $B$ the total mean age was 54.2 years with standard deviation 12.18. Out of 15 subjects 8 subjects right side of vestibular apparatus was affected and 7 subjects left side was affected in group $A$. In group B 6 subjects right side was affected and 9 subjects left side was affected. 
Table 2: Pre treatment and post treatment mean scores of DHI.

\begin{tabular}{|c|c|c|c|c|c|}
\hline Groups & Pre treatment & $\begin{array}{c}\text { Post } \\
\text { treatment }\end{array}$ & Difference & $\mathbf{t}_{14}$ & $\mathbf{p}$ \\
\hline $\begin{array}{c}\text { Epleys Maneuver with } \\
\text { postural restriction } \\
\text { (Group A) }\end{array}$ & $58.6 \pm 6.44$ & $13.6 \pm 2.84$ & $45 \pm 6.71$ & 26 & $<.001$ \\
\cline { 1 - 4 } $\begin{array}{c}\text { Epleys Maneuver (Group } \\
\text { B) }\end{array}$ & $60 \pm 6.84$ & $13 \pm 2.37$ & $47 \pm 6.88$ & 26.415 & $<.001$ \\
\hline $\mathrm{t}_{28}$ & 0.549 & 0.557 & 0.752 & & \\
\cline { 1 - 4 } $\mathrm{P}$ & 0.587 & 0.582 & 0.458 & \\
\hline
\end{tabular}

In Epleys Maneuver with postural restriction group pre treatment $\mathrm{DHI}$ mean score was $58.6 \pm$ 6.44 and post treatment mean score was with $13.6 \pm 2.84$ difference of $45 \pm 6.71$. When we compare between group A and group B pre treatment $p$ value was .549 which was not significant, post treatment was also not significant with $p$ value of .582 and difference was also not significant with $p$ value .458 . In group B pre treatment $\mathrm{DHI}$ mean score was $60 \pm 6.84$ and post treatment mean score was $13 \pm 2.37$ with a difference of $47 \pm 6.88$. In group $A$ and group $B$ pre and post dizziness reduced significantly with $p$ value $<001$.

\section{DISCUSSION}

This study was conducted to see the effect of postural restrictions after Epleys maneuver in the treatment of BPPV. In the current study Epleys maneuver with postural restriction group mean age was 50.1 years and 54.2 years in Epleys maneuver group, which suggests that BPPV is very common around the age of 50 . The literature also says that as the age advances chance of getting BPPV is more common [11]. In our study females were more affected with BPPV then the male subjects. Similar results were obtained by Sauron B, Dobler S [12]. The result of the current study shows that there was no effect of postural restriction because the group $B$ also shows same effect as that of the group $A$ with postural restrictions. Subjects were more comfortable without postural restrictions. Similar results were obtained by several authors $[13,14]$. Post treatment postural restrictions were not monitored by the therapist but it was asked to the subjects during post treatment recording. For two subjects Epleys maneuver was done for second time.

Limitations of the study: Size of the sample was small and study was done in single center so it is difficult to generalize for larger population, Postural restrictions were not monitored.

Feature scope of the study, Long term follow-up with recurrence rates of the subjects has to be checked.

\section{CONCLUSION}

Both Epleys maneuver with postural restrictions and Epleys maneuver group were equally effective in the treatment of BPPV. In routine BPPV treatment we can stop advising the postural restrictions to the subjects so that we can avoid the discomfort to the subjects because of postural restrictions.

\section{ABBREVIATIONS}

BPPV - Benign Paroxysmal Positional Vertigo.

DHI - Dizziness handicap inventory.

SCCs - Semicircular canals.

\section{Conflicts of interest: None}

\section{REFERENCES}

[1]. Neel Bhattacharyya, Reginald F, Baugh, Larura Orvidas, David Barrs, et al Clinical Practice Guideline: Benign Paroxysmal Positional Vertigo, Otolaryngology-head and neck surgery. 2008;137:S47S81.

[2]. John Graham and David Baguley, Ballantyne's Deafness, $7^{\text {th }}$ edition 2001 Whurr Publication Page no 272-285.

[3]. Susan J Herdaman, Vestibular rehabilitation $2^{\text {nd }}$ edition F. A Davisn company Philadelphia 451-475.

[4]. S. Korres, D. G. Balatsouras, A. Kaberos, C. Economou, D Kandiloros, and E. Ferekidis, Occurrence of semicircular canal involvement in benign paroxysmal positional vertigo," Otology and Neurotology, 2002;23(6):926-932.

[5]. Susan B O Sullivan, Thomas J. Schmitz, Physical rehabilitation $4^{\text {th }}$ edition Jaypee Brothers Medical publishers (P) Ltd, Page no 821-843.

[6]. Seung-Han Lee, Ji Soo Kim Benign Paroxysmal Positional Vertigo, J Clin Neurol. Jun2010;6(2):51-63.

[7]. Janet Odriy Helminski, David Samuel Zee, Imke Janssen, Timothy Carl Hain, Effectiveness of Particle Repositioning Maneuvers in the treatment of Benign Paroxysmal Positional Vertigo; Systematic Review Physical Therapy 2010;90(5):663-678.

[8]. Richard E. Gans, and Patricia A. Harrington-Gans, Au.D. Treatment Efficacy of Benign Paroxysmal Positional Vertigo (BPPV) with Canalith Repositioning Maneuver and Semont Liberatory Maneuver in 376 Patients. Seminars in hearing/volume 23. Number 22002 Pg no 129-141. 
[9]. George X. Papacharalampous, P. V. Vlastarakos, G. P. Kotsis, D. Davilis, and L.Manolopoulos. The Role of Postural Restrictions after BPPV Treatment: Real Effect on Successful Treatment and BPPV's Recurrence Rates International Journal of Otolaryngology. Volume 2012, Article ID 932847, 5 pages doi:10.1155/2012/932847.

[10]. Darcy A, Umphred, Neurological rehabilitation, $4^{\text {th }}$ edition Mosby.Inc.2001 USA, Pg no 616-660.

[11]. Patricia Q. McGinnis, Marissa Nebbia, Lisa Saez, Katherine Rudolph, Retrospective Comparison of Outcomes for Patients with Benign Paroxysmal Positional Vertigo Based on Length of Postural Restrictions Journal of Geriatric Physical Therapy 2009;32(4):168-173.
[12]. Sauron B, Dobler S. Benign paroxysmal positional vertigo. Diagnosis, course, physiopathology and treatment. Rev Prat. 1994;44(3):313-8.

[13]. G. Fyrmpas, D. Rachovitsas, A. B. Haidich et al. "Are postural restrictions after an Epley maneuver unnecessary? First results of a controlled study and review of the literature," Auris Nasus Larynx, 2009;36(6):637-643.

[14]. Michel Toupet, Evelyne Ferrary, and Alexis Bozorg Grayeli. Effect of Repositioning Maneuver Type and Post maneuver Restrictions on Vertigo and Dizziness in Benign Positional Paroxysmal Vertigo. The Scientific World Journal Volume 2012, Article ID 162123, 7 pages doi:10.1100/2012/162123.

\footnotetext{
How to cite this article:

Anil R Muragod, Sanjiv Kumar. THE EFFECT OF POSTURAL RESTRICTIONS IN THE TREATMENT OF BENIGN PAROXYSMAL POSITIONAL VERTIGO: RANDOMIZED CONTROL TRIAL. Int J Physiother Res 2017;5(3):2051-2055. DOI: $10.16965 /$ ijpr.2016.157
} 